\title{
EFEITO DA FERMENTAÇÃO NA QUALIDADE DE “CHIPS” DE MANDIOCA (Manihot esculenta Crantz) ${ }^{1}$
}

\author{
Regina Kitagawa GRIZOTTO², Hilary Castle de MENEZES ${ }^{2, *}$
}

\begin{abstract}
RESUMO
Foi investigado o efeito da fermentação natural da mandioca, isoladamente, ou em combinação com o cozimento em água em ebulição, na crocância dos "chips". As fatias de mandioca, oriundas de raízes previamente descascadas e limpas foram imersas em água potável a $30^{\circ} \mathrm{C}$ durante periodos de $8 \mathrm{~h}$ e $24 \mathrm{~h}$ e depois fritas. As raízes inteiras, descascadas e limpas, foram mantidas nas mesmas condições, porém por períodos mais longos: $24 \mathrm{~h}$, $30 \mathrm{~h}$ e $48 \mathrm{~h}$, após os quais as raízes foram fatiadas e fritas. A fermentação natural foi conduzida sem a adição de qualquer agente fermentativo, imergindo uma parte de fatias ou de raízes de mandioca em quatro partes de água potável a $30^{\circ} \mathrm{C}$, em estufa com controle de temperatura. Outras variáveis estudadas foram: variedades de mandioca e o formato das fatias. $\mathrm{O}$ efeito dos tratamentos foi avaliado com base na fraturabilidade dos "chips", medidos em Analisador de Textura TA.XT2. O formato das fatias pareceu ser um fator importante, pois afetou as características de textura dos "chips", além dos tratamentos propriamente ditos. O formato retangular das fatias, apesar do aspecto atrativo, foi considerado inadequado para a fabricação dos "chips", sendo sugerido o formato redondo. Foi verificado que a fermentação natural das raízes inteiras ou cortadas em fatias, isoladamente ou em combinação com o cozimento em água em ebulição, foi considerada uma técnica inadequada para tornar os "chips" de mandioca mais crocantes, visto que promoveram, na maioria dos casos, aumento na dureza comparado aos "chips" obtidos do controle. Estas observações foram válidas para todas as variedades estudadas: IAC Mantiqueira, IAC 576.70, IAC 13 e IAC 14.

Palavras-chave: mandioca "chips"; processamento; fermentação; crocância.
\end{abstract}

\section{SUMMARY}

EFFECT OF FERMENTATION ON THE QUALITY OF CASSAVA (Manihot esculenta Crantz) CHIPS. It was investigated the effect of natural fermentation of cassava, alone or combined with cooking in boiling water on the crispness of cassava chips. The thin slices of cassava, originally from previously peeled and cleaned roots were submerged in drinkable water at $30^{\circ} \mathrm{C}$ during periods of $8 \mathrm{~h}$ and $24 \mathrm{~h}$. The whole cassava roots, also peeled and cleaned were submitted on the same conditions, but for longer periods: $24 \mathrm{~h}$, $30 \mathrm{~h}$ and $48 \mathrm{~h}$, after those roots were sliced and fried. The natural fermentation was conducted without any fermentative agent, only submerging one part of thin slices or whole roots into four parts of drinkable water at $30^{\circ} \mathrm{C}$ in a controlled temperature incubator. The other variables studied were: cassava variety and slice format. The effect of the treatments was evaluated, based on the friability of the chips as measured by the Texture Analyzer TA.XT2. The format of the slices appeared to be an important factor, because it affected texture characteristics of the chips, as well as the actual treatments. The rectangular format, although attractive, was considered inadequate for the manufacture of chips, the round format being suggested as more suitable. It was shown that the natural fermentation of the whole roots or cut into thin slices, alone or combined with boiling was considered an inadequate technique to obtain crispness cassava chips, since in general, such treatments increased the hardness of the chips, as compared to the untreated samples. This observations were valuable from all the studied varieties: IAC Mantiqueira, IAC 576.70, IAC 13 and IAC 14

Keywords: cassava chips; processing; fermentation; crispness.

\section{1 - INTRODUÇÃO}

Tradicionalmente, a fermentação tem sido utilizada para melhorar o valor nutricional de alimentos ricos em carboidratos e de baixo teor protéico, melhorar a palatabilidade e as características de aroma [6]. A fermentação foi considerada como um dos processos mais tradicionais de desintoxicação da mandioca $[2,5,10]$. No entanto, a sua efetividade na eliminação dos compostos cianogênicos tem sido debatida por vários pesquisadores [1, 9, 18, 29, 31].

Existe uma grande variedade de produtos fermentados à base de mandioca consumidos no Brasil e na África que apresentam notáveis similaridades, como é

\footnotetext{
Recebido para publicação em 25/02/2002. Aceito para publicação em 10/02/2004 (000809). Apresentado no IV Simpósio Latino Americano de Ciência de Alimentos (SLACA), Campinas, SP em 14/11/2001. Parte do Trabalho de Tese de Doutorado em Tecnologia de Alimentos ( $1^{a}$ autora). 2. Departamento de Tecnologia de Alimentos, Faculdade de Engenharia de Alimentos, UNICAMP, Caixa Postal 13081-970, Campinas, SP. E-mail: hilary@feaunicamp.br

* A quem a correspondência deve ser enviada.
}

o caso do carimã ou mandioca puba ou simplesmente puba consumida na região Norte-Nordeste do Brasil [3], e o "lafun" e o "fufu" consumidos em países do oeste africano [24]. Ambos produtos, obrigatoriamente, envolvem a fermentação natural das raízes, sem adição de inóculos fermentativos, em algum estágio do processamento. As condições para se obter produtos fermentados submersos de qualidade estabelecidos por OYEWOLE [25] foram: imersão em água potável das raízes inteiras ou em pedaços por $48 \mathrm{~h}-60 \mathrm{~h}$ a $30-35^{\circ} \mathrm{C}$.

SOKARI \& WACHUKWU [29] verificaram que a maceração em água potável durante períodos de $24 \mathrm{~h}, 48 \mathrm{~h}$ e $72 \mathrm{~h}$ de fatias delgadas de mandioca previamente cozidas, promoveu decréscimo no valor de $\mathrm{pH}$ da água de maceração, confirmando que a fermentação é estabelecida nestes períodos. Este produto, denominado "ijapu", mandioca "chips" ou tapioca, é consumido em países africanos, como a Nigéria, após o enxágüe das fatias de mandioca macerada, como prato principal ou "snack". A denominação "chips", dada ao "ijapu”, parece estar relacionada com a espessura fina das fatias (1-3mm espessura), não tendo sido mencionada a etapa de fritura em óleo quente no fluxograma de processamento. 
Apenas recentemente a fermentação tem sido empregada para o desenvolvimento de novos produtos ou na melhoria da qualidade dos já existentes. AUKRUST, BLOM \& SLINDE [4] e SLINDE et al. [28] conseguiram através da fermentação láctica controlada $(24 \mathrm{~h}, 48 \mathrm{~h}$ e $72 \mathrm{~h}$ a $23^{\circ} \mathrm{C}$ ), reduzir os niveis de açúcares redutores e controlar a extensão das reações de Maillard, obtendo "chips" de cenoura fritos em óleo com coloração clara e sabor agradável. Em trabalho similar, MANAN et al. [19] inocularam fatias de batatas com $10^{8}$ UFC de Lactobacillus plantarum durante $12 \mathrm{~h}$ a $30-32^{\circ} \mathrm{C}$. Após a fritura em óleo quente, as batatas "chips" apresentaram coloração clara e elevada aceitabilidade. De acordo com JANKOWSKI, PARKIN \& VON-ELBE [14] o escurecimento não enzimático, ou reação de Maillard, que ocorre na superfície das batatas após a fritura, está relacionado com a distribuição heterogênea de glicose nas mesmas. A fermentação, neste caso, pode controlar a extensão da reação de Maillard, abaixando os níveis de açúcares redutores, como a glicose e a frutose, do vegetal, antes de ser submetido à fritura em altas temperaturas, proporcionado produtos finais mais claros e de sabor agradável [28].

O emprego da fermentação como uma forma de viabilizar a fabricação de "chips" de mandioca, no entanto, não foi encontrado na literatura.

CEREDA [7] observou que os microrganismos envolvidos na fermentação natural da fécula de mandioca ocorrem sem que um grupo específico prevaleça, sendo encontrados na maioria dos experimentos o Bacillus subtilis e o Leuconostoc citrovorum. MESTRES \& ROUAU [20] consideram a fermentação natural da fécula de mandioca ser essencialmente promovida por bactérias lácticas, onde o número de microrganismos lácticos aumenta rapidamente no período inicial (12 a 48 horas) da fermentação, favorecido pelo ambiente ácido.

ALMEIDA [3] cita que nas primeiras 24h da fermentação submersa há um aumento da população de Erwinia, Klebsiella, Corynebacterium e Streptococus, após o qual decrescem gradualmente até desaparecerem no terceiro dia da fermentação, sendo substituídos por Streptococus, Lactobacillus e Leuconostoc que predominam no final da fermentação. OKAFOR, IJIOMA \& OYOLU [21] verificaram que, para o mesmo tipo de fermentação submersa, somente os microrganismos dos gêneros Corynebacterium sp. e Bacillus sp. eram capazes de amolecer a raiz da mandioca através da produção de enzimas pectinolíticas e da desintegração de outros componentes celulares. Segundo os autores, as bactérias do ácido láctico abaixam o pH do meio para valores inferiores a 4, conferem aroma típico aos produtos de fermentação submersa como é o caso do "fufu", mas não promovem o amolecimento das raízes. Similarmente, OYEWOLE [25] relatou que durante o processo fermentativo do "lafun" e do "fufu", houve produção de enzimas amilases e pectina-metil-esterases capazes de promover o amaciamento das raízes de mandioca. OYEWOLE \& ODUNFA [23] verificaram que, durante o processo sucessório de dominação microbiana, cada grupo de microrganismo apresenta importante contribuição ao processo fermentativo, onde se incluem quebra do amido, acidificação, desintoxicação e desenvolvimento de aroma.

A inconstância na qualidade culinária das raízes de mandioca e a falta de controle sobre esta característica, tem sido um dos fatores que inviabilizam o processamento industrial da mandioca durante o ano todo [8]. As causas destas variações e a instabilidade dos cultivares são pouco conhecidas, podendo ser decorrentes de fatores intrínsecos e extrínsecos [16].

A hipótese de separação celular, proposta por Bettleheim, Sterling e Linehan, Hughes, ambos citados por SAFO-KANTANKA \& OWUSU-NIPAH [26], tenta elucidar as causas das variações na qualidade culinária das raízes e tubérculos. Esta hipótese explica que os produtos cozidos tornam-se farináceos em decorrência do afrouxamento das substâncias pécticas intercelulares podendo levar a liberdade das células; quando as células não são facilmente afrouxadas, o produto cozido torna-se não farináceo ou duro ou vítreo. O termo farináceo ou farinácea exprime a textura característica de raízes e tubérculos cozidos, sentida na boca. Em batatas é também definido como a propriedade do tubérculo desintegrar-se, espontaneamente, durante o cozimento e despedaçar-se pela ação de um garfo. SAFO-KANTANKA \& OWUSU-NIPAH [26] observaram que as células do tecido da mandioca mostravam-se desorganizadas somente quanto cozidas; nas raízes cozidas, porém não farináceas, as células mantiveram-se intactas, sem quaisquer diferenças nas características celulares.

A distribuição uniforme de açúcares e amido nas diferentes regiões da mandioca: região externa, localizada logo abaixo da casca, região intermediária e região central, próxima ao feixe de fibras, apresenta importante papel na qualidade culinária das raízes [22]. Raízes de qualidade culinária inferior geralmente apresentam baixo teor de amido na região central, invariavelmente inferior ao teor de açúcares nesta região. Por ocasião do cozimento, sendo baixo o teor de amido na região central, não há força de expansão suficiente para exercer pressão através da região intermediária rica em amido. Desta forma, o centro permanece não farináceo, enquanto a região intermediária torna-se parcialmente farinácea.

VITRAC et al. [32] produziram "chips" de mandioca fritos em óleo, a partir de fatias de raízes frescas. Entretanto, foi evidenciado pelos autores, a dificuldade de predizer o comportamento da matéria-prima durante a fritura e a qualidade do produto final.

GRIZOTTO \& MENEZES [11] demonstraram ser necessário o emprego de pré-tratamentos como o cozimento em água em ebulição ou em vapor saturado das fatias de mandioca, antes da fritura em óleo quente para se produzir "chips" de mandioca crocantes, com características similares ao da batata chips.

A crocância dos alimentos entre os quais se incluem as batatas chips, pode ser definido como sendo: 
"firme (rígido), quebra-se com facilidade quando forçado, emitindo som característico" [30], sendo o termo mais freqüentemente mencionado que qualquer outra palavra para descrever a textura dos "chips" de mandioca [12]. Entre os métodos objetivos utilizados para determinar a crocância de alimentos desidratados, o método de Bourne citado por JACKSON, BOURNE \& BARNARD [13] foi considerado satisfatório para determinação da crocância em "chips" de banana. Este método baseia-se na ruptura destes alimentos ao primeiro esforço, obtendo curvas força versus distância com nítidos picos de força a partir de testes de penetração.

Como a textura dura foi apontada como o principal empecilho que envolve a tecnologia de fabricação de “chips" de mandioca, supôs-se ser possivel torná-los crocantes porém macios, por meio da ação de enzimas produzidas durante a fermentação natural das raízes, que atuassem seletivamente sobre as substâncias pécticas presentes nos tecidos das raízes de mandioca e promovessem o afrouxamento entre as células dos tecidos, melhorando as características de textura do "chips" de mandioca.

O objetivo deste trabalho foi verificar o efeito de diferentes períodos de fermentação, isoladamente ou em combinação com o cozimento em água em ebulição na crocância dos "chips" de mandioca.

\section{2 - MATERIAL E MÉTODOS}

\section{1 - Matéria-prima}

Neste trabalho foram utilizados cerca de 80 quilos de cada uma das variedades de mandioca (Manihot esculenta Crantz): IAC Mantiqueira, IAC 576.70, IAC 13 (clone 44.82) e IAC 14 (clone 114.80), colhidas aos oito meses do plantio. As raízes, doadas pelo Núcleo Experimental de Campinas do Instituto Agronômico (IAC), situado em Campinas (S.P.), foram colhidas entre maio e setembro de 1996, e processadas no mesmo dia ou no prazo máximo de $24 \mathrm{~h}$.

\section{2 - Preparo dos "chips" de mandioca}

O fluxograma de trabalho para produção de "chips" de mandioca é mostrado na Figura 1.

Raízes de mandioca limpas, sem as cascas - película suberosa e feloderma, foram fatiadas mecanicamente no multiprocessador Hobart (The Hobart Mfg., Troy, Ohio, U.S.A.) em fatias delgadas com 1,1 a $1,5 \mathrm{~mm}$ de espessura, homogeneizadas e amostras representativas foram retiradas para serem utilizadas nos prétratamentos descritos no item 2.5.

As fatias foram fritas em fritador Croydon, (Rio de Janeiro, Brasil), modelo FSL, equipado com termostato e capacidade para 6 litros. Aproximadamente 4 quilos de gordura vegetal hidrogenada, própria para fritura (ponto de fusão $28^{\circ} \mathrm{C}$ ), foram suficientes para preencher o tacho e receber 35 a 40 fatias por operação. A temperatura da gordura durante a fritura foi controlada em torno de $170^{\circ} \mathrm{C}$ e o tempo variou de 2 a 2,5 minutos. Após a fritura os "chips" foram drenados em papel absorvente, resfriados, embalados em sacos de polietileno e armazenados em câmara de congelamento a $-25^{\circ} \mathrm{C}$, com circulação de ar, por no máximo 3 semanas até o momento da determinação da fraturabilidade.

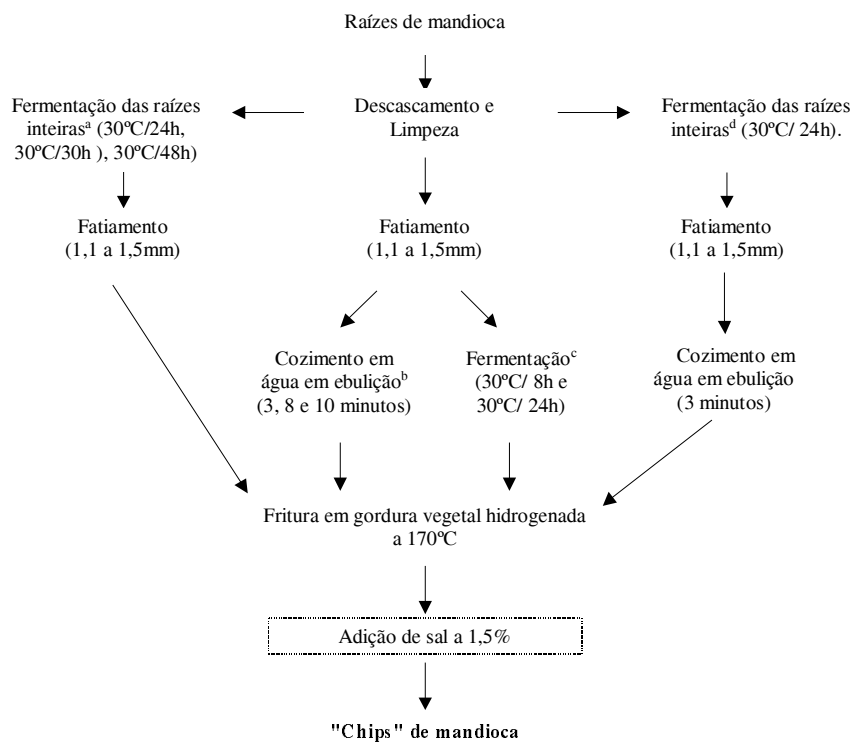

FIGURA 1. Fluxograma de produção de "chips" de mandioca com quatro opções de pré-tratamentos: (a) fermentação das raízes inteiras de mandioca; (b) cozimento em água em ebulição; (c) fermentação das fatias de mandioca; (d) fermentação das raízes inteiras de mandioca + cozimento em água em ebulição.

O produto obtido "chips" de mandioca foi definido como: "fatias delgadas de mandioca, pré-tratadas ou não, fritas em gordura vegetal”.

\section{3 - Formato redondo das fatias}

Raízes descascadas e limpas foram fatiadas no multiprocessador Hobart no sentido transversal ao feixe de fibras central, obtendo-se fatias redondas com 1,1 a $1,5 \mathrm{~mm}$ de espessura. Pressupôs-se, em cada fatia, haver distribuição homogênea das regiões externa, intermediária e central do cilindro rico em amido.

\section{4 - Formato retangular das fatias}

Raízes descascadas e limpas foram cortadas com auxílio de facas de aço inox, em toletes de aproximadamente $6 \mathrm{~cm}$ de comprimento e, em seguida, cortadas no multiprocessador Hobart no sentido longitudinal ao comprimento da raiz. As fatias assim obtidas, apresentavam o formato retangular, 1,1 a 1,5cm de espessura e provenientes de regiões distintas e eqüidistantes do feixe de fibras central.

\section{5 - Pré-tratamentos}

\subsection{1 - Fermentação das fatias de mandioca}

Lotes representativos de aproximadamente $800 \mathrm{~g}$ de fatias redondas ou retangulares de raízes frescas fo- 
ram imersos em água potável a $30^{\circ} \mathrm{C}$, na proporção de $1: 4$, e mantidos nesta temperatura durante $8 \mathrm{~h}$ e $24 \mathrm{~h}$ em estufa Fanen (Rio de Janeiro, Brasil) modelo 330, com controle de temperatura e circulação de ar. Após estes períodos, as fatias foram lavadas em água corrente, drenadas por aproximadamente 1 minuto e fritas em gordura vegetal a $170^{\circ} \mathrm{C}$. Nenhum agente de fermentação foi adicionado. Um lote de raízes frescas foi fatiado e frito, e os "chips" obtidos foram utilizados como controle.

\subsection{2 - Fermentação das raizes inteiras}

Lotes representativos de raízes inteiras de aproximadamente $800 \mathrm{~g}$ foram imersos em água potável (proporção de $1: 4)$ previamente aquecida a $30^{\circ} \mathrm{C}$, reservados em recipientes plásticos e mantidos na estufa Fanen. Após períodos de $24 \mathrm{~h}, 30 \mathrm{~h}$ e $48 \mathrm{~h}$ de fermentação as raízes foram lavadas em água corrente, cortadas nos formatos redondo e retangular e fritas em gordura vegetal a $170^{\circ} \mathrm{C}$. Não foi adicionado qualquer tipo de agente de fermentação. Um lote de fatias frescas foi frito sendo utilizado como controle.

\subsection{3 - Fermentação das raízes inteiras + cozi- mento em água em ebulição $(F+C)$}

Raízes inteiras de mandioca foram mantidas durante $24 \mathrm{~h}$ em água potável a $30^{\circ} \mathrm{C}$, na proporção de $1: 4$ na estufa Fanen. Após o período de fermentação as raízes foram lavadas em água corrente, fatiadas no formato redondo e cozidas em água em ebulição. Lotes representativos de aproximadamente 200 a $250 \mathrm{~g}$ de fatias de mandioca fermentadas foram dispostos em cestos de alumínio perfurado $(25 \mathrm{~cm}$ de diâmetro e $15 \mathrm{~cm}$ de altura) e imersos em água em ebulição. Ao final de 3 minutos o cesto foi retirado, as fatias foram resfriadas em água corrente, drenadas por 30 segundos e fritas em gordura vegetal a $170^{\circ} \mathrm{C}$. Um lote de fatias frescas foi frito imediatamente após o corte e utilizado como controle.

\subsection{4 - Cozimento em água em ebulição}

Lotes representativos de aproximadamente $300 \mathrm{~g}$ de fatias redondas ou retangulares de mandioca fresca foram dispostos em cestos de alumínio perfurado $(25 \mathrm{~cm}$ de diâmetro e $15 \mathrm{~cm}$ de altura) e imersos em água em ebulição. Ao final de três minutos, oito minutos e dez minutos, o cesto foi retirado, as fatias de mandioca foram resfriadas em água corrente, drenadas por 30 segundos e fritas em gordura vegetal a $170^{\circ} \mathrm{C}$. Nenhum agente de fermentação foi adicionado. Um lote de fatias frescas foi frito em gordura vegetal e serviu como controle.

\section{6 - Fraturabilidade}

A força requerida para a ruptura foi medida em Texture Analyzer TA.XT2, equipado com programa XTRAD Dimention da Stable Micro Systems, utilizando uma velocidade constante de $5 \mathrm{~mm} / \mathrm{s}$. As amostras de mandioca "chips" foram colocadas centralizadas sobre uma base cilíndrica de $3 \mathrm{~cm}$ de diâmetro, e uma sonda tipo bola com $1 / 4$ de polegada foi abaixada até a ruptura da amostra, a uma distância de $6,0 \mathrm{~mm}$ do ponto inicial. Um gráfico de força versus tempo foi obtido e os resultados expressos em gramas, representando a média de seis picos de força máxima com respectivos erros padrões (ED) expressos em porcentagem.

O modelo matemático completo que explica a fraturabilidade dos "chips" ( $\mathrm{Frt}_{\mathrm{ijk}_{\mathrm{j}}}$ ) foi supostamente formado pela adição dos seguintes efeitos:

Frt. $_{i \mathrm{jk}}=\mu+\alpha_{\mathrm{i}}+\beta_{\mathrm{j}}+(\alpha \beta)_{\mathrm{ij}}+\mathrm{E}_{\mathrm{ijk}}$

(equação 1)

onde $\mu$ = efeito geral ou média geral; $\alpha_{i}=$ efeito devido ao i-ésimo tratamento; $\beta_{\mathrm{j}}=$ efeito devido ao j-ésima variedade; $\alpha \beta_{\mathrm{ij}}=$ efeito devido a interação do i-ésimo tratamento com o j-ésima variedade; $\mathrm{i}=1, \ldots, \mathrm{a} ; \mathrm{j}=1, \ldots, \mathrm{b}$; $\mathrm{k}=1, \ldots, \mathrm{n}$ e $\mathrm{E}_{\mathrm{ijk}}=$ efeito da interação da k-ésima unidade experimental do j-ésimo tratamento assumindo-se distribuição normal $\left(0, \alpha^{2}\right)$.

\section{7 - Análise estatística}

Os resultados da fraturabilidade foram submetidos ao programa estatístico "Statistical Analysis Systems" [27] para cálculo do nível de significância e o teste de Tukey que comparou a média dos tratamentos.

\section{3 - RESULTADOS E DISCUSSÃO}

A fraturabilidade de duas marcas diferentes de batatas fritas (marcas A e B) e um extrusado de milho (marca C) foi determinada para servir de referência e indicar o valor de fraturabilidade que os "chips" deveriam atingir para serem considerados comestiveis (Tabela 1).

TABELA 1. Fraturabilidade ${ }^{(1)}$ em gramas de salgadinhos tipo "snacks" encontrados no mercado.

\begin{tabular}{cccc}
\hline Produto & Fatias & Marca comercial & Fraturabilidade \\
\hline Batata frita & Ondulada & A & $353,42 \pm 32,59$ \\
Batata frita & Lisa & B & $572,33 \pm 84,12$ \\
Extrusado de milho & Lisa & C & $513,05 \pm 45,98$ \\
\hline
\end{tabular}

(1) média de 6 determinações \pm erro padrão; onde erro padrão $=\mathrm{s} .(\sqrt{ } \mathrm{n})^{-1} ; \mathrm{s}^{2}=\left[\sum \mathrm{x}^{2}-\left(\sum \mathrm{x}\right)^{2} /\right.$ $\mathrm{n}] .(\mathrm{n}-1)^{-1} ; \mathrm{n} \rightarrow \mathrm{n} .^{\circ}$ de amostras.

\section{1 - Efeito do formato das fatias de mandioca}

O formato das fatias pareceu ser um fator importante, pois afetou as características de textura dos "chips", além dos tratamentos propriamente ditos. Quando se testou o formato dos "chips" de mandioca, em particular para a variedade IAC 576.70 considerada a mais consistente, foi observada redução significativa na fraturabilidade dos "chips" de formato redondo (Tabela 2) e retangular (Tabela 3). Entretanto, os "chips" de formato redondo da IAC 576.70 submetidos ao cozimento em água em ebulição durante 8 e 10 minutos e os previamente fermentados durante $8 \mathrm{~h}$ e $24 \mathrm{~h}$, apresentaramse $36 \%$ mais crocantes que os equivalentes de formato retangular. Foi observado que, durante a condução des- 
tes experimentos, as fatias retangulares quebraram-se com mais freqüência que as fatias redondas.

As fatias retangulares utilizadas nas determinações da fraturabilidade foram as que mantiveram seus formatos, provavelmente aquelas oriundas da região central do cilindro da raiz da mandioca, próxima ao feixe do xilema, também chamado de pavio da mandioca por LIMA [15]. Sabe-se que nesta região da mandioca, a distribuição de amido e de açúcares no sentido radial das raízes pode variar tanto quanto no sentido longitudinal das mesmas [15], o que reflete diretamente na qualidade culinária da mandioca [16].

O formato retangular das fatias de mandioca, apesar de bastante atrativo, parece não ser recomendado para a fabricação de "chips" de mandioca. Considerando-se a aparência do produto, a elevada freqüência de quebra das fatias contrapõe-se à importância de manter a integridade das mesmas, sendo mais indicado o formato redondo quando se emprega pré-tratamentos de fermentação ou de cozimento.

\section{2 - Efeito da fermentação natural das fatias de mandioca}

O estudo de diferentes períodos de fermentação mostrou resultados distintos de acordo com as variedades em estudo e a forma com que as raízes foram submetidas à fermentação: em fatias redondas (Tabela 2) ou retangulares (Tabela 3).

TABELA 2. Efeito do cozimento e da fermentação das fatias redondas na fraturabilidade ${ }^{(1)}$ (em g) de "chips" de mandioca variedades IAC 576.70, IAC Mantiqueira, IAC 13 e IAC 14

\begin{tabular}{|c|c|c|c|c|c|}
\hline \multirow{3}{*}{$\begin{array}{l}\text { Variedades } \\
\qquad I A C\end{array}$} & \multirow{3}{*}{ Controle } & \multicolumn{4}{|c|}{ Pré-tratamentos } \\
\hline & & \multicolumn{2}{|c|}{ Cozimento $^{(2)}$ (minutos) } & \multicolumn{2}{|c|}{ Fermentação ${ }^{(3)}$ (horas) } \\
\hline & & 8 & 10 & 8 & 24 \\
\hline Mantiqueira & $1006,5 \pm 206,2$ & $706,8 \pm 44,9$ & $389,9 \pm 39,2$ & $615,2 \pm 25.5$ & $642,9 \pm 27,4$ \\
\hline 576.70 & $1109,3 \pm 156,4$ & $542,5 \pm 31,3$ & $458,3 \pm 33,0$ & $774,3 \pm 52,3$ & $518,3 \pm 34,3$ \\
\hline 13 & $856,9 \pm 46,4$ & $680,6 \pm 67,4$ & $642,7 \pm 67,4$ & $507,1 \pm 42,3$ & $763,1 \pm 44.9$ \\
\hline 14 & $1173,2 \pm 96,6$ & $700,8 \pm 38,8$ & $564,3 \pm 47,3$ & $634,1 \pm 52,0$ & $656,7 \pm 49,5$ \\
\hline MÉDIA ${ }^{(4)}$ & $1036,47^{a}$ & $657,67^{b}$ & $513,80^{b}$ & $632,67^{b}$ & $645,25^{b}$ \\
\hline
\end{tabular}

(1) média de 6 determinações \pm erro padrão. ${ }^{(2)}$ cozimento das fatias redondas em água em ebulição, amostradas após 8 e 10 minutos, seguido da drenagem e fritura em gordura vegetal a $170^{\circ} \mathrm{C}$. ${ }^{(3)}$ fermentação das fatias redondas em água potável a $30^{\circ} \mathrm{C}$, amostradas após $8 \mathrm{~h}$ e $24 \mathrm{~h}$, seguida da drenagem e fritura em gordura vegetal cativamente entre si pelo teste de Tukey $(\mathrm{p} \leq 0,05)$.

Os "chips" de formato redondo, oriundos das quatro variedades estudadas, apresentaram uniformidade de resultados frente aos pré-tratamentos a que foram submetidos (Tabela 2).

A efetividade do efeito dos pré-tratamentos ( $\mathrm{p} \leq 0,0001)$ e o conseguinte efeito interativo com as variedades ( $\mathrm{p} \leq 0,018)$ na fraturabilidade dos "chips" de formato redondo foram confirmados pelos elevados niveis de significância obtidos pela análise de variância. As variedades, no entanto, apresentaram efeito não significativo $(\mathrm{p}=0,4252)$ e foram consideradas estatisticamente iguais.
O teste de comparação múltipla - Teste de Tukey verificou que, para a média das quatro variedades, os "chips" pré-tratados apresentaram valores de fraturabilidade significativamente inferior $(\mathrm{p} \leq 0,05)$ comparados aos obtidos do controle. Entre os pré-tratamentos não foram verificadas diferenças significativas.

Analisando os valores individuais de fraturabilidade dos "chips", podemos observar que o cozimento por 10 minutos foi o pré-tratamento que promoveu menores valores de fraturabilidade: $389 \mathrm{~g}$ com erro padrão de $39,2 \mathrm{~g}$ para a variedade IAC Mantiqueira, e $458 \mathrm{~g}$ com erro padrão de $42,3 \mathrm{~g}$ para a IAC 576.70. Estes valores de fraturabilidade são comparáveis, respectivamente, ao da batata frita (marca A) e do extrusado de milho (marca C) (Tabela 1), servindo como referência para classificar os "chips" de mandioca pré-cozidos como crocantes e comestiveis.

Considerando o erro padrão, a fraturabilidade da batata frita (marca B) pode variar de $490 \mathrm{~g}$ a $660 \mathrm{~g}$. Como a fermentação promoveu "chips" com valores dentro desta faixa de variação, poderíamos dizer que a fermentação também promoveu "chips" crocantes.

TABELA 3. Efeito do cozimento e da fermentação das fatias retangulares na fraturabilidade ${ }^{(1,2)}$ (em g) de "chips" de mandioca variedades IAC Mantiqueira, IAC 576.70, IAC 13 e IAC 14

\begin{tabular}{cccccc}
\hline \multirow{2}{*}{$\begin{array}{c}\text { Variedades } \\
\text { IAC }\end{array}$} & Controle & \multicolumn{4}{c}{ Pré-tratamentos } \\
\cline { 3 - 6 } & & 8 & 10 & 8 & 24 \\
\hline & & Cozimento $^{(3)}$ (minutos) & Fermentação $^{(4)}$ (horas) \\
\hline Mantiqueira & $1063,3 \pm 145,5^{\text {a }}$ & $964,8 \pm 55,5^{\mathrm{b}}$ & $717,5 \pm 111,7^{\mathrm{b}}$ & $1403,7 \pm 93,9^{\mathrm{a}}$ & $767,4 \pm 60,8^{\mathrm{b}}$ \\
576.70 & $1684,7 \pm 216,9^{\mathrm{a}}$ & $877,4 \pm 54,1^{\mathrm{b}}$ & $891,1 \pm 108,0^{\mathrm{b}}$ & $943,4 \pm 34,9^{\mathrm{b}}$ & $894,6 \pm 109,0^{\mathrm{b}}$ \\
13 & $1017,2 \pm 87,4^{\mathrm{a}, \mathrm{b}, \mathrm{c}, \mathrm{d}}$ & $1258,9 \pm 104,8^{\mathrm{a}}$ & $898,3 \pm 57,2^{\mathrm{b}}$ & $893,0 \pm 57,5^{\mathrm{b}, \mathrm{c}}$ & $755,7 \pm 41,7^{\mathrm{b}, \mathrm{d}}$ \\
14 & $1351,5 \pm 128,5^{\mathrm{a}}$ & $861,7 \pm 72,5^{\mathrm{a}}$ & $1232,9 \pm 277,7^{\mathrm{a}}$ & $1013,3 \pm 65,0^{\mathrm{a}}$ & $1461,5 \pm 220,7^{\mathrm{a}}$ \\
\hline
\end{tabular}

(1) média de 6 determinações \pm erro padrão. ${ }^{(2)}$ médias seguidas por letras diferentes, na mesma linha, diferem significativamente entre si pelo teste de Tukey $(p \leq 0,05)$. ${ }^{(3)}$ cozimento das fatias retangulares em água em ebulição, amostradas após 8 e 10 minutos, seguido da drenagem e fritura em gordura vegetal a $170^{\circ} \mathrm{C}$. (4) fermentação das fatias retangulares em água potável a $30^{\circ} \mathrm{C}$, amostradas após $8 \mathrm{~h}$ e $24 \mathrm{~h}$, seguida da drenagem e fritura em gordura vegetal a $170^{\circ} \mathrm{C}$.

Quanto aos "chips" de formato retangular, podemos observar na Tabela 3 que a IAC Mantiqueira e a IAC 576.70 foram as variedades que proporcionaram “chips" cozidos (8min. e 10min.) e fermentados $(8 \mathrm{~h} \mathrm{e}$ 24h) com valores de fraturabilidade mais baixos comparados aos "chips" obtidos do controle. Exceção feita para os "chips" da variedade IAC Mantiqueira fermentados por 8 horas, cuja fraturabilidade obtida foi equivalente ao controle.

A variedade IAC 14 pareceu não ter sido afetada pelo cozimento ou pela fermentação, visto que os "chips" obtidos apresentaram-se tão duros quanto o controle. Comportamento semelhante foi observado para a variedade IAC 13, entretanto, diferenças na fraturabilidade foram percebidas entre os "chips" cozidos por $8 \mathrm{e}$ 10 minutos e os fermentados durante 8 e 24 horas. Surpreendentemente, os "chips" da variedade IAC 13 cozidos por 8 minutos apresentaram-se muito duros 
(1259g), significativamente mais duros que os cozidos por 10 minutos (898g) e os fermentados por 8 horas (893g) e 24 horas $(755,7 g)$. Este comportamento diferenciado de cada variedade em relação aos pré-tratamentos é confirmado pelos níveis significativos do efeito variedade $(\mathrm{p} \leq 0,0238)$ e interação variedade e tratamento $(\mathrm{p} \leq 0,0001)$.

As variedades IAC 13 e 14, indicadas para o uso industrial segundo LORENZI [17], nem sempre apresentam características farináceas e distribuição uniforme de açúcares e amido nas diferentes regiões da raiz de mandioca, a exemplo do que acontece nas variedades de mesa. As mandiocas de qualidade culinária inferior, quando cozidas, geralmente apresentam o centro não farináceo, enquanto que a região intermediária torna-se parcialmente farinácea, de acordo com o relatório da FAO, citado por BALAGOPALAN et al. [6]. Estas constatações talvez expliquem a elevada freqüência com que as fatias retangulares quebraram e a ineficácia do cozimento e da fermentação na melhoria da qualidade dos "chips" de fatias retangulares das variedades IAC 13 e IAC 14.

\section{3 - Efeito da fermentação natural das raízes in- teiras.}

Foi estudado o efeito da fermentação durante períodos de $24 \mathrm{~h}, 30 \mathrm{~h}$ e $48 \mathrm{~h}$ das raízes inteiras, limpas e descascadas submersas em água potável a $30^{\circ} \mathrm{C}$. A combinação da fermentação por $24 \mathrm{~h}$ com cozimento em água em ebulição por 3 minutos, simbolizada por $\mathrm{F}+\mathrm{C}$, também foi investigada e os resultados para as variedades IAC 576.70, IAC 13 e IAC 14 são mostrados na Tabela 4. A variedade Mantiqueira não foi utilizada neste experimento por falta de material.

TABELA 4. Efeito da fermentação das raízes inteiras na fraturabilidade $^{(1,2)}$ (em g) de "chips" de mandioca, fatias redondas, variedades IAC 576.70, IAC 13 e IAC 14

\begin{tabular}{|c|c|c|c|c|c|}
\hline \multirow{3}{*}{$\begin{array}{l}\text { Variedades } \\
\qquad \text { IAC }\end{array}$} & \multirow{3}{*}{ Controle } & \multicolumn{4}{|c|}{ Pré-tratamentos } \\
\hline & & \multicolumn{3}{|c|}{ Fermentação ${ }^{(3)}$ (horas) } & \multirow{2}{*}{$F+C^{(4)}$} \\
\hline & & 24 & 30 & 48 & \\
\hline 576.70 & $701,5 \pm 63,38^{a, b}$ & $585,8 \pm 41,6^{b}$ & $889,5 \pm 56,1^{a}$ & $828,2 \pm 34,7^{a}$ & $561,2 \pm 62,3^{b}$ \\
\hline 13 & $945,4 \pm 44,8^{a, b}$ & $990,5 \pm 53,5^{\text {a b }}$ & $1012,0 \pm 46,8^{a, b}$ & $1149,1 \pm 101,5^{a}$ & $791,7 \pm 56,7^{b}$ \\
\hline 14 & $665,4 \pm 39,6^{d}$ & $969,3 \pm 70,2^{b, c}$ & $1096,9 \pm 54,4^{\mathrm{a}, \mathrm{b}}$ & $1210,1 \pm 75,9^{a}$ & $892,0 \pm 47,5^{\circ}$ \\
\hline \multicolumn{6}{|c|}{ 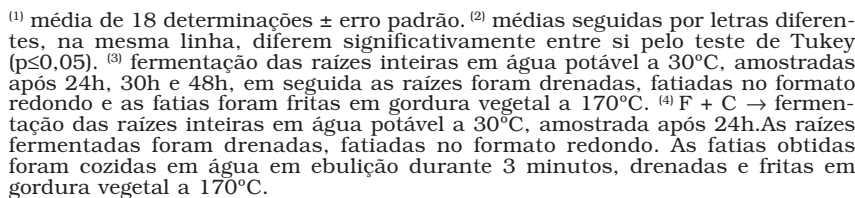 } \\
\hline
\end{tabular}

A evolução da fermentação pode ser acompanhada pelo razoável turvamento da água com liberação de gases, verificado pela presença de bolhas na superfície e odor característico de fermentação. Não foi percebido qualquer amolecimento das raízes após os períodos de fermentação de $24 \mathrm{~h}, 30 \mathrm{~h}$ e $48 \mathrm{~h}$.
A análise de variância indicou que o modelo da fraturabilidade dos "chips" foi significativo ( $\mathrm{p} \leq 0,0001)$ e os fatores: tratamentos $(p \leq 0,0001)$, variedade $(p \leq 0,0001)$ e interação tratamento-variedade $(\mathrm{p} \leq 0,0001)$ exerceram efeitos significativos na característica de textura dos "chips". Interação significativa entre pré-tratamentos e variedades, implica em dizer que a resposta dada pela fraturabilidade dos "chips" varia de acordo com a variedade e o tipo de pré-tratamento que foi empregado.

O teste de Tukey mostrou que a fraturabilidade dos "chips" fermentados das variedades IAC 576.70 e IAC 13 apresentou valores equivalentes entre estes "chips" e os obtidos do controle, mesmo quando se combinou a fermentação com o cozimento em água em ebulição $(\mathrm{F}+\mathrm{C})$.

Para a variedade IAC 14, o mesmo teste de comparação múltipla, indicou que os "chips" fermentados apresentaram-se mais duros que o controle, e a dureza aumentou à medida que se prolongou o tempo de fermentação para $30 \mathrm{~h}$ e $48 \mathrm{~h}$. Para esta variedade, a combinação entre a fermentação e o cozimento também não promoveu melhoria na crocância dos "chips".

Assim, baseando-se nos resultados obtidos deste experimento, podemos concluir que a fermentação das raízes inteiras, por períodos de $24 \mathrm{~h}, 30 \mathrm{~h}$ e $48 \mathrm{~h}$, não promoveu melhorias nas características de textura dos "chips" de mandioca, mesmo em combinação com o cozimento. Sendo esta observação válida para as variedades IAC 576.70, IAC 13 e IAC 14.

SLINDE et al., [28] observaram que a fermentação láctica de fatias de cenoura promoveu modificações na textura dos "chips" de cenoura fritos em óleo percebidas durante a mastigação, sendo sugerido que tais modificações pudessem ser decorrentes das alterações nos componentes do tecido da cenoura. Embora os detalhes destas alterações não estejam completamente elucidadas, elas são reconhecidas e desejadas, como, por exemplo, em picles fermentado. Considerando que tais informações possam ser aplicadas à mandioca, a fermentação pode ter alterado a textura dos "chips" a um tal ponto que, mesmo em combinação com o cozimento em água em ebulição, não foi suficiente para torná-los crocantes.

No experimento com as variedades IAC Mantiqueira, IAC 13 e IAC 14 (Tabela 5), foi investigado o efeito de cada pré-tratamento isoladamente: fermentação das raízes inteiras durante $24 \mathrm{~h}$, o cozimento em água em ebulição por 3 minutos e o efeito da combinação destes pré-tratamentos $(\mathrm{F}+\mathrm{C})$. A variedade IAC 576.70 não foi utilizada neste experimento por falta de material.

A análise de variância mostrou que a probabilidade dos tratamentos $(\mathrm{p} \leq 0,0008)$ e das variedades $(\mathrm{p} \leq 0,0001)$ afetarem ou influenciarem as características de textura dos "chips" foi significativo. No entanto, o efeito da interação tratamento versus variedade foi não significativo $(\mathrm{p}=0,2824)$. A ausência da interação pode ser traduzida pelo comportamento praticamente idêntico das variedades, independente dos tratamentos a que foram submetidos. 
TABELA 5. Efeito da fermentação das raízes inteiras na fraturabilidade $^{(1)}$ (em g) de "chips" de mandioca, fatias redondas, variedade IAC Mantiqueira; IAC 13 e IAC 14

\begin{tabular}{|c|c|c|c|c|c|}
\hline \multirow{3}{*}{$\begin{array}{l}\text { Variedades } \\
\text { IAC }\end{array}$} & \multirow{3}{*}{ Controle } & \multicolumn{3}{|c|}{ Pré-tratamentos } & \multirow{3}{*}{$\begin{array}{c}\text { Média } \\
\text { Pré- } \\
\text { tratamentos }^{(5)}\end{array}$} \\
\hline & & $\begin{array}{c}\text { Fermentação }^{(2)} \\
\text { (horas) }^{(2)}\end{array}$ & $\begin{array}{c}\text { Cozimento }^{(3)} \\
\text { (minutos) }\end{array}$ & \multirow[t]{2}{*}{$\mathrm{F}+\mathrm{C}^{(4)}$} & \\
\hline & & 24 & 3 & & \\
\hline Mantiqueira & $719,7 \pm 60,1$ & $677,7 \pm 49,2$ & $583,9 \pm 44,6$ & $620,9 \pm 44,4$ & $650,55^{a}$ \\
\hline 13 & $847,7 \pm 62,7$ & $723,1 \pm 47,6$ & $812,7 \pm 53,6$ & $618,4 \pm 53,3$ & $750,47^{b}$ \\
\hline 14 & $898,9 \pm 66,3$ & $757,2 \pm+66,9$ & $868,4 \pm 51,8$ & $634,7 \pm 77,3$ & $789,8^{b}$ \\
\hline $\begin{array}{c}\text { Média } \\
\text { Variedades }\end{array}$ & $817,12^{a}$ & $719,34^{a, b}$ & $755,01^{a}$ & $624,71^{b}$ & \\
\hline
\end{tabular}

(1) média de 12 determinações \pm erro padrão. (2) fermentação das raízes inteiras em água potável a $30^{\circ} \mathrm{C}$, amostrada após $24 \mathrm{~h}$. As raízes fermentadas foram drenadas, fatias redondas em água em ebulicão por 3 minutos, drenadas e fritas em gordura vegetal a $170^{\circ} \mathrm{C} .{ }^{(4)} \mathrm{F}+\mathrm{C} \rightarrow$ fermentação das raizes inteiras em água potável a $30^{\circ} \mathrm{C}$ amostrada após $24 \mathrm{~h}$. As raízes fermentadas foram drenadas, fatiadas no formato redondo. As fatias obtidas foram cozidas em água em ebulição durante 3 minutos, drenadas e fritas em gordura vegetal a $170^{\circ} \mathrm{C}$. ${ }^{(5)}$ médias dos pré-tratamentos seguidas por letras diferentes, na mesma coluna, diferem significativamente entre si pelo test de Tukey (p $\leq 0,05)$.
linha, diferem significativamente entre si pelo teste de Tukey $(p \leq 0,05)$.

O teste de Tukey, neste caso, calculou a média entre as variedades e a média entre os pré-tratamentos, para verificar possiveis diferenças. Podemos observar, para a média das variedades, que tanto a fermentação das raízes inteiras por $24 \mathrm{~h}$ como o cozimento das fatias por 3 minutos não foram suficientes para melhorar a crocância dos "chips". A combinação destes pré-tratamentos $(\mathrm{F}+\mathrm{C})$, no entanto, proporcionou redução significativa $(\mathrm{p} \leq 0,05)$ nos valores de fraturabilidade dos "chips" de mandioca quando comparados com o controle. Pelas médias dos pré-tratamentos, a IAC Mantiqueira foi a variedade que apresentou "chips" mais crocantes. Estes resultados apontam a IAC Mantiqueira e a fermentação das raízes inteiras durante $24 \mathrm{~h}$ seguida do cozimento das fatias por 3 minutos $(\mathrm{F}+\mathrm{C})$ como o "par": variedade e pré-tratamento que apresentou as menores médias de fraturabilidade, 650,55g e 624,71g, respectivamente. Porém estes valores não atingiram o padrão determinado nos produtos similares comercializados.

\section{4 - CONCLUSÕES}

- A fermentação natural das raízes inteiras ou cortadas em fatias, isoladamente, ou em combinação com o cozimento em água em ebulição, dentro das condições estabelecidas neste trabalho, não foi considerada uma técnica adequada para se produzir "chips" comestiveis obtidos das variedades IAC Mantiqueira, IAC 576.70, IAC 13 e IAC 14.

- As fatias de formato retangular quebraram-se com maior freqüência do que as de formato redondo, sendo consideradas inadequadas para a fabricação de "chips" de mandioca. Sugerimos o formato redondo das fatias para a fabricação dos "chips", tendo em vista a manutenção da integridade das fatias.

- A IAC Mantiqueira e IAC 576.70, consideradas de uso culinário, foram as variedades que apresen- taram maior susceptibilidade à fermentação no que se referiu a diminuição da fraturabilidade dos "chips". Porém, os valores de fraturabilidade determinados não atingiram o padrão dos produtos similares comercializados.

- As variedades IAC 13 e IAC 14, indicadas para a produção de farinha e fécula, não apresentaram resultados promissores quando se empregou a fermentação como tratamento prévio para a fabricação de "chips" de mandioca.

- O cozimento em água em ebulição durante 10 minutos das fatias de mandioca variedades IAC Mantiqueira e IAC 576.70 proporcionou "chips" crocantes e comestiveis, baseando-se nos valores de fraturabilidade.

\section{5 - REFERÊNCIAS BIBLIOGRÁFICAS}

[1] AALBersberG, W.G.L.; LiMAlevU, L. Cyanide content in fresh and processed fijian cassava (manihot esculenta) cultivars. Tropical Sci., v. 31, n. 3, p. 49-256, 1991.

[2] AKINRELE, I.A. Fermentation of cassava. J. Sci. Food Agri., v. 15, n. 5, p. 589, 1964.

[3] ALMEIDA, P.F. Fermentação da mandioca para produção de carimã. Ciênc. Tecnol. Aliment., v. 13, n. 2, p. 113120, 1993.

[4] AUKRUST, T.; BLOM, H.; SLINDE, E. Influence of brine composition on yield and quality of deep-fried fermented carrot chips. Lebens Wiss Tecnol., v. 28 n. 1, p. 100-104, 1995.

[5] AYERNOR, G.S. Effects of the retting cassava on product yield and cyanide detoxification. J. Food Tech., v. 20, n. 1, p. 89-96, 1985.

[6] BALAGOPALAN, C.; PADMAJA, G.; NANDA, S.K.; MOORTHY, S.D. Cassava Foods. In: Balagopalan C et al. (ed.) Cassava in Food, Feed and Industry. Boca Raton: Crc Press. p. 97-100, 103-106, 110-111, 1988.

[7] CEREDA, M.P. Alguns aspectos sobre a fermentação da fécula de mandioca. (Dissertação de Mestrado). 89p. 1973. Faculdade de Ciências Médicas e Biológicas de Botucatu, Universidade Estadual Paulista, Brasil.

[8] CEREDA, M.P. Desafios do processamento da mandioca. In: Encontro Nacional sobre Processamento Mínimo de Frutas e Hortaliças, 2. Viçosa. Palestras... Viçosa, MG: Universidade Federal de Viçosa. p 140-146. 2000.

[9] COOKE, R.D.; MADUAGWU, E.N. The effect of simple processing on the cyanide content of cassava chips. J. Food Tech., v. 13, n. 4, p. 299-306, 1978.

[10] EZEALA, D.O.; OKORO, N. Processing techniques and hydrocyanic acid content of cassava-basead human foodstuffs in Nigeria. J. Food Biochm., v. 10, n. 2, p. 125-132, 1986.

[11] GRIZOTTO, R.K.; MENEZES, H.C. Effect of cooking on the crispness of cassava chips. J. Food Sci., v. 67, n. 3, p. 1219-1223, 2002.

[12] GRIZOTTO, R.K.; MENEZES, H.C. Avaliação da aceitação de "chips" de mandioca. Ciênc. Tecnol. Aliment., 23(suplemento). (No prelo) 2003.

[13] JACKSON, J.C.; BOURNE, M.C.; BARNARD, J. Optimization of blanching for crispness of banana chips using response surface methodology. J. Food Sci., v. 61, n. 1, p. 165-166, 1996. 
[14] JANKOWSKI, K.M.; PARKIN, K.L.; VON-ELBE, J.H. Nonuniform browning or "motting" in french fry products associated with heterogeneous distribuition of reducing sugar. J. Food Proc. Pres., v. 21, n. 1, p. 33-53, 1997.

[15] LIMA, U.A. 1982. Industrialização da mandioca. In: Câmara GMS, Godoy CP, Marcos Filho J, Lima UA, editores. Mandioca: Produção, Pré-Processamento e Transformação Agroindustrial. Série Agroindustrial n. ${ }^{\circ} 4$. São Paulo: Secretaria da Ind., Com., Ciência e Tec. p 1-44.

[16] LORENZI, J.O. Variação na qualidade culinária das raízes de mandioca. Bragantia. v. 53, n. 2, p. 237-245, 1994.

[17] LORENZI, J.O. Mandioca. Campinas: CATI, 2003. p. 18-20. (Boletim Técnico, 245)

[18] MADUAGWU, E.N.; OBEN, D.H.E. Effects of processing of grated cassava roots by the "screw press" and by traditional fermentation methods on the cyanide content of gari. J. Food Tech., v. 13, n. 3, p. 299-302, 1981.

[19] MANAN, J.K.; JOSHI, G.J.; SAXENA, A.K.; KALRA, C.L.; BERRY, S.K. Improvement in color of deep fat fried potato chips from cold stored potatoes by lactic acid fermentation (Lactobacillus Plantarum). J. Food Sci. Tech., v. 24, n. 3, p. 139-141, 1987.

[20] MESTRES, C.; ROUAU, X. Influence of natural fermentation and drying conditions on the physicochemical characteristics of cassava starch. J. Sci. Food Agric., v. 74, n. 2, p. 147-155, 1997.

[21] OKAFOR, N.; IJIOMA, B.; OYOLU, C. Studies of the microbiology of cassava retting for foo-foo production. J. App Bact., v. 56, n. 1, p. 1-13, 1984.

[22] ONWUEME, I.C. The Tropical Tuber Crops. New York: John Wiley and Sons. p. 112-113, 1978.

[23] OYEWOLE, O.B.; ODUNFA, S.A. Microbiological studies on cassava fermentation for "lafun" production. Food Microb., v. 5, n. 3, p. 125-133, 1988.

[24] OYEWOLE, O.B.; ODUNFA, S.A. Characterization and distribution of lactic acid bacteria in cassava fermentation during "fufu" production. J. App Bact., v. 68, n. 2 , p. $145-152,1990$.

[25] OYEWOLE, O.B. Fermentation of cassava for lafun and fufu production in Nigeria. Food Lab News, v. 7 , n. 2, p. 29-31, 1991.

[26] SAFO-KANTANKA, O.; OWUSU-NIPAH, J. Cassava varietal screening for cooking quality: relationship between dry matter, starch content, mealiness and certain microscopic observation of the raw and cooked tuber. J. Sci. Food Agric., v. 60, n. 1, p. 99-104, 1992.

[27] SAS Systems For Windows 3.95. 1992. SAS Institute, Inc. Cary, NC, USA.

[28] SLINDE, E.; SKREDE, G.; AUKRUST, T.; BLOM, H.; BAARDSETH, P. Lactic acid fermentation influence on sugar content and color of deep-fried carrot chips. Food Res Int., v. 26, n. 4, p. 255-260, 1993.

[29] SOKARI, T.G.; WACHUKWU, C.K. Detoxification of ijapu, a fermented cassava product similar to potato chips. Tropical Sci., v. 33, n. 2, p. 145-151, 1993.

[30] SZCZESNIAK, A.S. The meaning of textural characteristics - crispness. J. Tex Stud., v. 19, n. 1, p. 51-59, 1988.

[31] VASCONCELOS, A.T.; TWIDDY, D.R.; WESTBY, A.; REILLY, P.J.A. Detoxification of casava during gari preparation. Int J. Food Sci. Tech., v. 25, n. 2, p. 189203, 1990.

[32] VITRAC, O.; DUFOUR, D.; TRYSTRAM, G.; RAOULTWACK, A.L. Deep-fat frying of cassava: influence of raw material properties on chip quality. J. Sci. Food Agric., v. 81, n. 2, p. 227-236, 2000.

\section{6 - AGRADECIMENTOS}

A autora RKG agradece ao CNPq pela concessão de Bolsa de Doutorado. 